\title{
Alcohol dependence induced in rats by semivoluntary intermittent intake
}

M.S. Macieira,

W.G. Almeida,

E.A. Silva,

L.C. Schenberg and

E.M. Nakamura-Palacios
Departamento de Ciências Fisiológicas, Centro Biomédico,

Universidade Federal do Espírito Santo, Vitória, ES, Brasil

\author{
Correspondence \\ E.M. Nakamura-Palacios \\ Programa de Pós-Graduação \\ em Ciências Fisiológicas \\ Centro Biomédico, UFES \\ Av. Marechal Campos, 1468 \\ 29040-090 Vitória, ES \\ Brasil \\ Fax: 55 (027) 335-7330 \\ The authors are recipients of \\ the following CNPq fellowships: \\ Predoctoral (M.S. Macieira), \\ Undergraduate (W.G. Almeida and \\ E.A. Silva) and Research \\ (L.C. Schenberg and E.M. \\ Nakamura-Palacios).
}

Received September 17, 1996

Accepted July 11, 1997

\begin{abstract}
The objective of the present experiment was to assess ethyl alcohol (ETOH) dependence brought about by a semivoluntary intermittent intake regimen in rats. Male Wistar rats weighing 150-250 $\mathrm{g}$ at the onset of the experiment were assigned to the following groups: $0 \%$ ETOH $(\mathrm{N}=11), 5 \%$ ETOH $(\mathrm{N}=20), 20 \% \mathrm{ETOH}(\mathrm{N}=20)$ and $40 \%$ ETOH $(\mathrm{N}=18)$. ETOH solutions were offered at the end of the day and overnight from Monday to Friday, and throughout weekends, for 90 days. The concentration of the ETOH solutions was increased in a stepwise fashion allowing the rats to get used to the taste of alcohol. Reposition of pure water was permitted during 1-h water drinking periods in the morning. Daily volume intake ( \pm SEM) averaged $25.4 \pm$ $0.4 \mathrm{ml}(0 \% \mathrm{ETOH}), 23.8 \pm 0.6 \mathrm{ml}(5 \% \mathrm{ETOH}), 17.6 \pm 0.7 \mathrm{ml}(20 \%$ $\mathrm{ETOH})$ and $17.5 \pm 0.6 \mathrm{ml}(40 \% \mathrm{ETOH})$. ETOH consumption differed significantly $(\mathrm{P}<0.05)$ among groups, averaging $4.4 \pm 0.2 \mathrm{~g} \mathrm{~kg}^{-1} \mathrm{day}^{-1}$ (5\% ETOH), $10.3 \pm 0.3 \mathrm{~g} \mathrm{~kg}^{-1} \mathrm{day}^{-1}(20 \% \mathrm{ETOH})$ and $26 \pm 1.2 \mathrm{~g} \mathrm{~kg}^{-1}$ day $^{-1}$ (40\% ETOH). Furthermore, ETOH detection in plasma 10-12 h after offering the solution indicated that its consumption in the $40 \%$ ETOH group was sufficient to override its metabolism. Overt signs of ETOH dependence, such as increased thirst, hyperactivity, puffing, hair ruffling and startle responsiveness as well as reduced drowsiness, were significantly increased in the $20 \%$ and $40 \%$ ETOH groups compared to the $0 \%$ and $5 \%$ groups. Accordingly, the model described here proved to be a useful tool for the evaluation of subtle or moderate behavioral and physical consequences of long-term ETOH intake.
\end{abstract}

Experimental dependence on ethyl alcohol (ETOH) is usually induced by 3 methods of drug administration: involuntary, semivoluntary or voluntary (1). While the involuntary method refers to the forced drug administration by gastric intubation or by the intravenous, intraperitoneal and pulmonary routes (2), in the semivoluntary method ETOH is offered as part of a liquid or food
Key words

- Ethanol

- Alcohol

- Drug dependence

- Rat diet, which is ingested spontaneously (3), and in the voluntary method the animals have to learn to self-administer the drug (4). Both advantages and disadvantages have been observed for each procedure. Thus, whereas the involuntary method is quite suitable for the evaluation of the development of tolerance and early signs of physical dependence $(1,5)$, the procedure is rather ag- 
gressive and often produces severe consequences. On the other hand, while the spontaneous oral intake of ETOH greatly favors the semivoluntary method, dehydration, which is not a common feature in clinical practice, may supervene as a consequence of long-term ETOH administration in which the drug solution is the only source of liquid. Finally, although the voluntary method is quite useful for the assessment of the reinforcing properties of ETOH, its higher cost and technical difficulties are the major drawbacks of its use. The aim of the present study was to establish a simple model of induction of ETOH dependence by means of a semivoluntary intermittent daily intake of different concentrations of the drug.

Two-month old male Wistar rats weighing 150-250 $\mathrm{g}$ at the beginning of the experiment were placed in individual cages with food ad libitum. Rats were randomly assigned to four groups: $0 \% \mathrm{ETOH}(\mathrm{N}=11)$, $5 \%$ ETOH $(\mathrm{N}=20), 20 \%$ ETOH $(\mathrm{N}=20)$ and $40 \% \mathrm{ETOH}(\mathrm{N}=18)$, according to treatment, i.e., tap water for the $0 \% \mathrm{ETOH}$ control group and 5\%, 20\% and 40\% ETOH solutions for the remaining groups. Rats were weighed twice a week and the solutions were offered at the end of the day and kept overnight from Monday to Friday, and throughout the weekends. The concentration of the ETOH solutions was increased in a stepwise fashion allowing the rats to get used to the taste of alcohol. Weekly concentration increments to $5 \%, 10 \%$ and $20 \%$ were used in the first three weeks for the $5 \%, 20 \%$ and $40 \%$ ETOH groups, respectively. The concentration of the $40 \%$ ETOH group was further increased in steps to $30 \%$ and $40 \%$ in the fourth and fifth week, respectively. Once the desired ETOH concentration was attained, the solution was kept unchanged up to the completion of the 90-day treatment. Daily ETOH consumption, in gram per kilogram body weight $\left(\mathrm{g} \mathrm{kg}^{-1} \mathrm{day}^{-1}\right)$, was only evaluated after the fifth week when all groups received a stable concentration of ETOH.
Daily reposition of pure water was permitted during 1-h water drinking periods in the morning. Immediately thereafter, the ingested volume of water or ETOH solution was measured and behavioral responses indicative of physical dependence were recorded as present or not.

Mean weekly frequencies of behavioral responses were calculated for the following behavioral items: thirst (strong approach behavior to the bottle and vigorous drinking), hyperactivity (sudden quick movements during bottle replacement), startle response (sudden jump induced by finger snapping or key shaking near the cage), puffing (rapid respiratory movements), drowsiness (resting posture with eyes closed or semi-closed and apparent muscle relaxation as suggested by the lowering of the trunk and/or head and flexion of the limbs), and hair ruffling (piloerection).

Daily ETOH consumption was later confirmed by means of a biochemical assay in a separate set of experiments. Thus, rats were submitted to the same alcohol intake regimen, i.e., $0 \% \mathrm{ETOH}(\mathrm{N}=5), 5 \% \mathrm{ETOH}(\mathrm{N}=$ 6), $20 \% \mathrm{ETOH}(\mathrm{N}=6)$ and $40 \% \mathrm{ETOH}(\mathrm{N}=$ 6 ), but only for 30 days. At the end of treatment, rats were anesthetized with ethyl ether and two blood samples were drawn from the tail artery, 2-4 h (1st sample) and 10-12 $\mathrm{h}$ (2nd sample) after withdrawal of the ETOH solutions. Blood samples were then centrifuged and plasma ETOH levels were determined by enzymatic assay (Sigma Diagnostics Alcohol Reagent, St. Louis, MO) using a spectrophotometer (Gilford Instruments, model 250, Oberlin, $\mathrm{OH}$ ).

Alcohol intake and biochemical data were analyzed by two-way analysis of variance for repeated measures followed by the post hoc Tukey test and by the Student $t$-test of least square means, respectively. Weight gain was assessed by regression analysis. Behavioral scores were evaluated by nonparametric Kruskal-Wallis ANOVA followed by a post hoc nonparametric Tukey-like test (6). 
Data are reported as the mean \pm SEM and differences were considered to be significant at $\mathrm{P}<0.05$.

Rats weighed $192.2 \pm 17.6 \mathrm{~g}(0 \% \mathrm{ETOH})$, $180.5 \pm 14.8 \mathrm{~g}(5 \% \mathrm{ETOH}), 218.2 \pm 13.6 \mathrm{~g}$ $(20 \% \mathrm{ETOH})$ and $181.1 \pm 4.8 \mathrm{~g}(40 \% \mathrm{ETOH})$ at the onset of the experiment and $395.5 \pm$ $14.1 \mathrm{~g}(0 \% \mathrm{ETOH}), 328 \pm 15.2 \mathrm{~g}(5 \% \mathrm{ETOH})$, $354.2 \pm 11.4 \mathrm{~g}(20 \% \mathrm{ETOH})$ and $289.4 \pm 6.8$ $\mathrm{g}(40 \% \mathrm{ETOH})$ at the end of the experiment. There was a significantly smaller weight gain in the 5\% and $40 \%$ ETOH rats compared to the other groups $(\mathrm{P}<0.003)$ (Figure $1 C)$. Nonetheless, linear regression analysis showed a significant weight gain for all groups $(\mathrm{P}<0.001)$ throughout the experiment: $0 \% \operatorname{ETOH}(\mathrm{Y}=208.4+12.3 \mathrm{x}, \mathrm{r}=0.95), 5 \%$ ETOH ( $\mathrm{Y}=187.8+11.0 \mathrm{x}, \mathrm{r}=0.98), 20 \%$ $\mathrm{ETOH}(\mathrm{Y}=229.2+10.0 \mathrm{x}, \mathrm{r}=0.96)$ and $40 \%$ $\mathrm{ETOH}(\mathrm{Y}=191.2+7.2 \mathrm{x}, \mathrm{r}=0.97)$.

Daily volume intake averaged $25.4 \pm 0.4$ $\mathrm{ml}(0 \%$ ETOH $), 23.8 \pm 0.6 \mathrm{ml}(5 \%$ ETOH $)$, $17.6 \pm 0.7 \mathrm{ml}(20 \% \mathrm{ETOH})$ and $17.5 \pm 0.6 \mathrm{ml}$ $(40 \%$ ETOH) (Figure 1A). The 5\%, 20\% and $40 \%$ ETOH groups drank smaller amounts in the first week than the $0 \% \mathrm{ETOH}$ group $(\mathrm{P}<0.05)$. Compared to control rats, the 5\% ETOH group showed a lower volume intake during the first six weeks $(\mathrm{P}<0.05)$, but did not differ from controls thereafter. The $20 \%$ and $40 \%$ ETOH groups drank smaller volumes than the $0 \%$ and 5\% ETOH groups from the second week onwards $(\mathrm{P}<0.05)$. Moreover, compared to the $0 \%$ and $5 \%$ ETOH groups, a further decrease in volume intake was observed in the $20 \%$ and $40 \%$ ETOH groups after the increase of the alcohol concentration in the third and fifth weeks $(\mathrm{P}<0.05)$ (Figure 1A). ETOH consumption also differed significantly $(\mathrm{P}<0.05)$ among groups, averaging $4.4 \pm 0.2 \mathrm{~g} \mathrm{~kg}^{-1} \mathrm{day}^{-1}$ (5\% ETOH), $10.3 \pm 0.3 \mathrm{~g} \mathrm{~kg}^{-1} \mathrm{day}^{-1}(20 \% \mathrm{ETOH})$ and $26 \pm 1.2 \mathrm{~g} \mathrm{~kg}^{-1} \mathrm{day}^{-1}$ (40\% ETOH). Thus, ETOH consumption increased proportionally to alcohol concentration $(\mathrm{P}<0.05)$ (Figure 1B).

Daily evaluation of behavioral responses

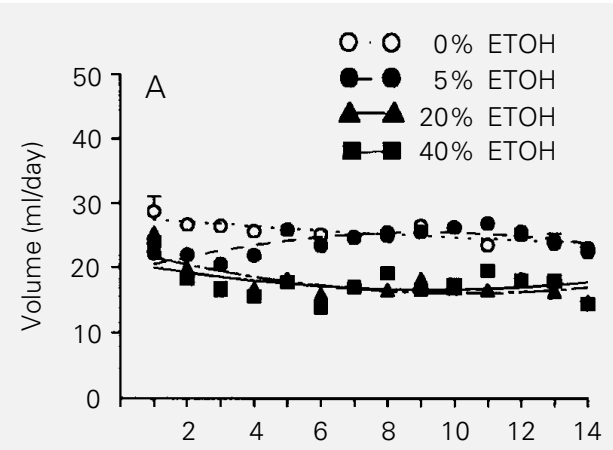

Figure 1 - Semivoluntary intermittent alcohol intake by rats. Data are reported as mean \pm SEM for tap water $(\mathrm{N}=11), 5 \%$ ethanol ( $N=20), 20 \%$ ethanol $(\mathrm{N}=20)$ and $40 \%$ ethanol ( $\mathrm{N}=$ 18). A, Daily volume intake of alcohol solutions (ml/day); $B$ daily ethanol (ETOH) consumption per $\mathrm{kg}$ body weight $(\mathrm{g} \mathrm{kg}$ body weight ${ }^{-1}$ day $^{-1}$ ); $C$, body weight (g) of rats during a 14week exposure to tap water or $5 \%, 20 \%$ and $40 \%$ alcohol solutions.
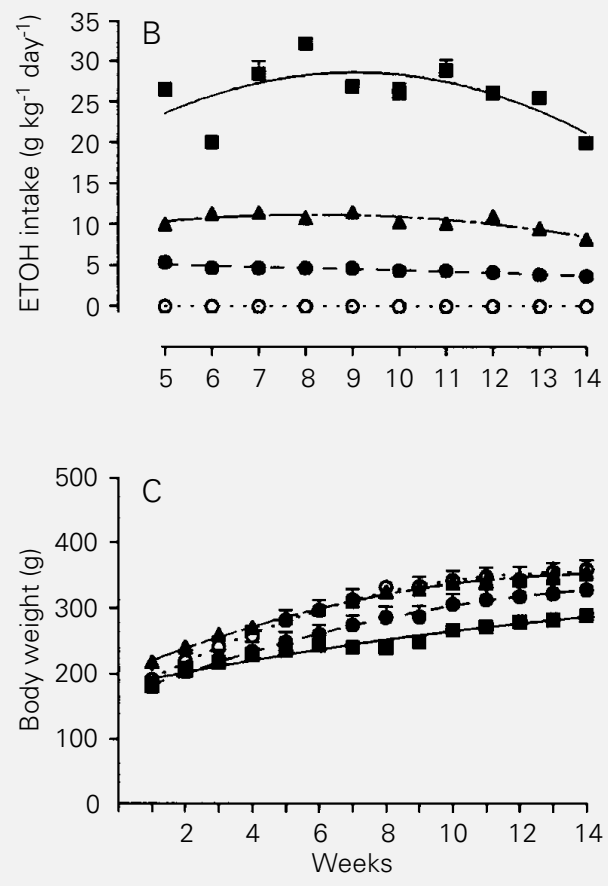

during the alcohol withdrawal period showed dose-dependent increases in thirst, hyperactivity and startle behavior and a dose-dependent decrease in drowsiness $(\mathrm{P}<0.05)$. Overt autonomic signs, i.e., puffing and hair ruffling, also showed a dose-dependent increase $(\mathrm{P}<0.05)$ (Table 1).

Compared to the corresponding background levels of the $0 \%$ ETOH group, there was a significant increase in plasma ETOH $10-12 \mathrm{~h}$ after the $40 \%$ solution was offered $(\mathrm{P}<0.01)$. Indeed, slightly increased levels were already detected 2-4 $\mathrm{h}$ after the presentation of the $40 \%$ ETOH solution $(\mathrm{P}<0.12)$ and 10-12 $\mathrm{h}$ after the presentation of the $5 \%$ 
ETOH solution $(\mathrm{P}<0.13)$. However, no changes were observed for the $20 \% \mathrm{ETOH}$ group (Table 2).

Alcohol concentrations of 5\%,20\% and $40 \%$ are close to those usually found in beer, wine and spirits, respectively. These solutions were offered in a regimen similar to that observed in either episodic or heavy human drinkers. Moreover, in spite of the daily offering of tap water, ETOH consumption was quite high, ranging from 4.4 up to $26 \mathrm{~g} \mathrm{~kg}^{-1}$ day $^{-1}$, a consumption similar to that used in many studies employing the semivoluntary method in which the ETOH solution was the only available source of liquid (7). Alcohol intake of $11.1 \mathrm{~g} \mathrm{~kg}^{-1} \mathrm{day}^{-1}$ after a 12-week treatment with $20 \%$ ETOH solution (8), or $8 \mathrm{~g} \mathrm{~kg}^{-1}$ day $^{-1}$ after an 8-week treatment with $15 \%$ ETOH solution (9), or even $11.6 \mathrm{~g} \mathrm{~kg}^{-1}$ day $^{-1}$ with a mild $9 \%$ ETOH solution after a 4-week treatment only (10), has been reported. Thus, in spite of the natural aversion of rats to the taste of alcohol (1), the present data suggest that rats on an intermittent alcohol intake regimen are able to drink large amounts of the solution. Furthermore, biochemical plasma analyses showed that the ETOH intake exceeded the rate of alcohol metabolism. Indeed, although the sampling time may not reflect the actual daily pattern of ingestion, plasma ETOH levels significantly higher than those for con-

Table 1 - Mean week frequency of behavioral responses recorded $1 \mathrm{~h}$ after the removal of the alcohol solution.

Data are reported as means $\times 100 \pm$ SEM. ${ }^{*} \mathrm{P}<0.05$ compared to $0 \% \mathrm{ETOH}$ ${ }^{+} \mathrm{P}<0.05$ compared to $0 \%$ and $5 \% \mathrm{ETOH}$ (nonparametric Tukey test).

\begin{tabular}{lrrrr}
\hline $\begin{array}{l}\text { Behavioral } \\
\text { responses }\end{array}$ & \multicolumn{4}{c}{ Treatment } \\
\cline { 2 - 5 } & $0 \%$ ETOH & $5 \%$ ETOH & $20 \%$ ETOH & $40 \%$ ETOH \\
\hline Thirst & $6.1 \pm 1.0$ & $21.1 \pm 1.9$ & $64.9 \pm 4.4^{*}$ & $75.2 \pm 7.9^{+}$ \\
Hyperactivity & $5.4 \pm 1.8$ & $11.3 \pm 1.9$ & $26.3 \pm 3.7^{*}$ & $48.2 \pm 4.6^{+}$ \\
Startle & $54.8 \pm 2.3$ & $62.1 \pm 3.7$ & $78.7 \pm 2.0^{*}$ & $87.6 \pm 1.7^{+}$ \\
Puffing & $4.4 \pm 1.4$ & $16.5 \pm 3.0^{*}$ & $19.7 \pm 2.9^{*}$ & $45.9 \pm 6.7^{+}$ \\
Hair ruffling & $70.0 \pm 2.9$ & $88.4 \pm 3.1^{*}$ & $94.4 \pm 1.4^{*}$ & $95.5 \pm 1.5^{*}$ \\
Drowsiness & $21.5 \pm 3.2$ & $16.7 \pm 2.2$ & $8.3 \pm 1.5^{*}$ & $4.6 \pm 1.7^{+}$
\end{tabular}

trols were found $10-12 \mathrm{~h}$ after offering the $40 \%$ ETOH solution. Plasma ETOH levels, however, were lower than the levels reported 15 min after acute intraperitoneal administration of $0.5 \mathrm{~g} / \mathrm{kg}$ and $1 \mathrm{~g} / \mathrm{kg}$ of $\mathrm{ETOH}$, which produced plasma concentrations of $50 \mathrm{mg} / \mathrm{dl}$ and $107 \mathrm{mg} / \mathrm{dl}$, respectively $(1,11$, 12).

Signs of physiological dependence on alcohol are often inferred from behavioral changes brought about by removal of the alcoholic solution $(7,13)$. Accordingly, hyperexcitability of the central nervous system, including audiogenic convulsions, trembling, spasticity, hyperactivity and increased responsiveness to environmental stimuli such as startle, irritability and hypervigilance, as well as autonomic responses such as tachypnea and tachycardia, were commonly described during abstinence of rats chronically treated with ETOH (7). Nevertheless, the virtual absence of physical dependence is often alleged as a major drawback of the oral intake of ETOH (1). Although severe responses which follow involuntary administration $(1,7,14)$ were not observed in the present study, overt signs indicating drug dependence were demonstrated for all groups, including increased puffing and hair ruffling in the 5\% ETOH group. Nevertheless, the absence of heavy signs of dependence favors oral ETOH intake as a reliable model for

\begin{tabular}{|c|c|c|}
\hline \multicolumn{3}{|c|}{$\begin{array}{l}\text { Table } 2 \text { - Plasma alcohol levels of tail arter } \\
\text { samples withdrawn } 2-4 \mathrm{~h} \text { and } 10-12 \mathrm{~h} \text { after offer } \\
\text { ing the alcohol solution. } \\
\text { Data are reported as means } \pm \text { SEM (mg/dl) } \\
{ }^{*} \mathrm{P}<0.01 \text { compared to } 0 \% \text { ETOH (Student } t \text {-test o } \\
\text { least square means). }\end{array}$} \\
\hline Group & 1st Sample & 2nd Sample \\
\hline 0\% ЕTOH & $2.2 \pm 1.1$ & $2.1 \pm 1.0$ \\
\hline $5 \% \mathrm{ETOH}$ & $4.5 \pm 1.8$ & $7.4 \pm 2.1$ \\
\hline $20 \% \mathrm{ETOH}$ & $5.5 \pm 0.8$ & $2.5 \pm 1.7$ \\
\hline $40 \% \mathrm{ETOH}$ & $6.8 \pm 3.3$ & $11.1 \pm 3.9^{*}$ \\
\hline
\end{tabular}


inducing mild or moderate alcohol dependence, a pattern most likely to be found in human drinkers. In conclusion, the present model proved to be a useful tool for the evaluation of subtle or moderate physical and behavioral consequences of long-term ETOH intake.

\section{References}

1. Pohorecky LA (1981). Animals analog of alcohol dependence. Federation Proceedings, 40: 2056-2064.

2. Crandall DL, Ferraro GD, Lozito RJ, Cervoni P \& Clark LT (1989). Cardiovascular effects of intermittent drinking: assessment of a novel animal model of human alcoholism. Journal of Hypertension, 7: 683-687.

3. Chan TCK \& Sutter MC (1983). Ethanol consumption and blood pressure. Life Sciences, 33: 1965-1973.

4. Meish RA \& Thompson T (1974). Rapid establishment of ethanol as a reinforcer for rats. Psychopharmacology, 37: 311321.

5. Walker DW, Hunter BE \& Abraham WC (1981). Neuroanatomical and functional deficits subsequent to chronic ethanol administration in animals. Alcoholism: Clinical and Experimental Research, 5: 267282.

\section{Acknowledgments}

We are deeply grateful to Dr. Adércio João Marquezini for help with the biochemical assays. We are also thankful to Simone Maria Bazzarella and Jozué Moreira de Sousa for technical assistance.
6. Zar JH (1984). Biostatistical Analysis. Prentice-Hall International, Inc., Englewood Cliffs, NJ.

7. Mello NK (1973). A review of methods to induce alcohol addiction in animals. Pharmacology, Biochemistry and Behavior, 1: 89-101.

8. Chan TCK \& Sutter MC (1982). The effects of chronic ethanol consumption on cardiac function of rats. Canadian Journal of Physiology and Pharmacology, 60: 777782.

9. Pires JGP, Cabral AM, Vasquez EC \& Bissoli NS (1993). Effect of high ethanol intake on vascular reactivity to serotonin, vasopressin and acetylcholine in normotensive rats. Journal of International Medical Research, 21: 133-137.
10. File SE, Andrews N \& Al-Farhan M (1993). Anxiogenic responses of rats on withdrawal from chronic ethanol treatment: effects of tianeptine. Alcohol and Alcoholism, 28: 281-286.

11. Pohorecky LA \& Brick J (1982). A new method for the determination of blood ethanol levels in rodents. Pharmacology Biochemistry and Behavior, 16: 693-696.

12. Pohorecky LA, Brick J \& Carpenter JA (1986). Assessment of the development of tolerance to ethanol using multiple measures. Alcoholism: Clinical and Experimental Research, 10: 616-622.

13. Woods JH \& Winger GD (1974). Alcoholism and animals. Preventive Medicine, 3 : 49-60.

14. Ellis FW \& Pick JR (1973). Animal models of ethanol dependency. Annals of the New York Academy of Sciences, 263: 215-217. 